\title{
Frequency Regulation of Micro-grid Connected Hybrid Power System with SMES
}

\author{
Shailendra Singh ${ }^{1} \cdot$ Rohit Kumar Verma ${ }^{2}$ Ashish Kumar Shakya ${ }^{3}$. \\ Satyendra Pratap Singh ${ }^{1}$
}

Received: 25 October 2015 / Accepted: 26 June 2017 / Published online: 22 July 2017

(C) Springer Nature Singapore Pte Ltd. 2017

\begin{abstract}
This paper presents the frequency regulation analysis of a micro-grid connected hybrid power system based on solar Photovoltaic (PV), Wind and Diesel-Engine Generator (DEG) with Superconducting Magnetic Energy Storage system (SMES) unit. Abrupt change in load demand and power fluctuations from PV and wind power source causes frequency variability in the system. In order to mitigate this issue, the hybrid power system incorporates along with the energy storage devices. A case study of the impact of SMES operations on the performance of frequency stability of hybrid system has been carried out. Simulation of a Hybrid Power System (HPS) model has been carried out in two different scenarios with the two phases. First is the steady state investigation of HPS using PI controller with step load change response. Second is the dynamic performance study throughout a typical day with arbitrary variation in load demands. Controller parameters are tuned with Genetic Algorithm based optimization approach. The limits on the inductor (coil) current due to the possibilities of discontinuous conduction in the presence of large disturbances and limited storage capacity have also been incorporated. HPS has analyzed in the Matlab Simulink environment. Simulation results indicate that SMES system
\end{abstract}

Shailendra Singh

ssingh.rs.eee14@itbhu.ac.in

1 Electrical Engineering Department, Indian Institute of Technology (BHU), Varanasi, India

2 Electrical Engineering Department, Indian Institute of Technology (ISM), Dhanbad, India

3 Electrical Engineering Department, GLA University, Mathura, India can contribute towards the frequency stability in both cases for variable power generations from renewable sources and irregular demand loads.

Keywords Renewable power - Photovoltaic · Energy storage · SMES · Micro-grid · Frequency stability · Hybrid power system

\section{Introduction}

The adverse effect of the greenhouse gases on atmosphere and decreasing fossil fuel reserves drags attentions towards clean and pollution free energy. In modern era, the leading clean energy sources are hydro energy, solar energy, wind energy and biogas mainly [1,2]. Moreover, generations from the wind and solar have enhanced their contribution in most of the world's electricity generation [3].The primary application of solar power system is to provide power to the off-grid area where the extension of the grid is not possible. However, wind power is more commonly used for grid integrations. Solar PV arrays have more installation flexibility and can be easily mounted on domestic locations [4]. In the current scenario, the wind, and solar PV power plants are widely deployed for distributed generations and microgrids (MGs). Generated power from PV and wind sources is variable in nature; it can be used to compensate the load demand locally and/or injected into local grids [5]. Renewable technology is also facing a lot of technical, economic and social barriers because of their intermittency nature and uncertainty issues [6]. Moreover, the interconnection of these renewables into the grids/MGs creates some technical problems such as frequency and voltage regulations. Operational issues in distributed system also raised due to high/low penetrations of distributed renewable sources [7]. Therefore, 
these problems need the attention of researchers and regulatory authorities to provide the best feasible solution. In this article, the frequency regulation issue raised during the operation of MG connected HPS has been discussed. The frequency stability of the system is mainly affected by mismatching of load generation balance and irregular loadings. Therefore, energy storage technology has been introduced to mitigate the frequency stability issue in micro-grid. Currently, storage technologies are capable of handling multifunctional tasks as backup powers, active/reactive power injection or absorption from/to the grid [8-10]. The conventional energy storage such as Battery energy storage system, Hydro pump storage, etc. is proposed by various researchers in the literature [11-13]. However, these storages have several problems such as high response time, limited Lifecycle, storage capacity, large unit volume and hazardous environmental impact, etc. Therefore, in this paper, SMES based technology has been proposed for the stable operation of hybrid power system. The potential capabilities such as fast response, inherently huge storage efficiency and injecting/ absorbing real or reactive power ability endorse the SMES as a viable solution $[14,15]$. The effect of SMES during the transient disturbance condition for a grid-connected power system has been analyzed in [15]. Various authors [15-17] have presented the application of SMES with the on grid and off grid mode. Neural network based frequency control of single and two area system is well documented in [18]. Authors in [19] have been presented the power flow control and management scheme with energy storage devices. A knowledge domain based concept for power flow controller has been discussed in [20]. Various efforts had been carried out by the authors to minimize the frequency fluctuation in hybrid power system with SMES in $[4,5,21]$.

This paper presents the extension work performed previous research work in [16]. However, for the aspect of novelty of the following additional work has been incorporated in this paper. (I) Small stability analysis of the solar based hybrid system with step load response (II) System frequency response has been controlled with PI controller. (III) Controller parameters are tuned with Genetic Algorithm based optimization approach. (IV) An additional hybrid power system based on purely renewable power generation is analyzed with SMES. The effect of SMES during the steady and dynamic state operation has also been discussed in this study.

\section{Description and Modeling of HPS}

In this section, description and modeling of hybrid power system have been carried out. Figure 1 shows the schematic diagrams of HPS connected to the microgrid. HPS is categories in three parts as follows:

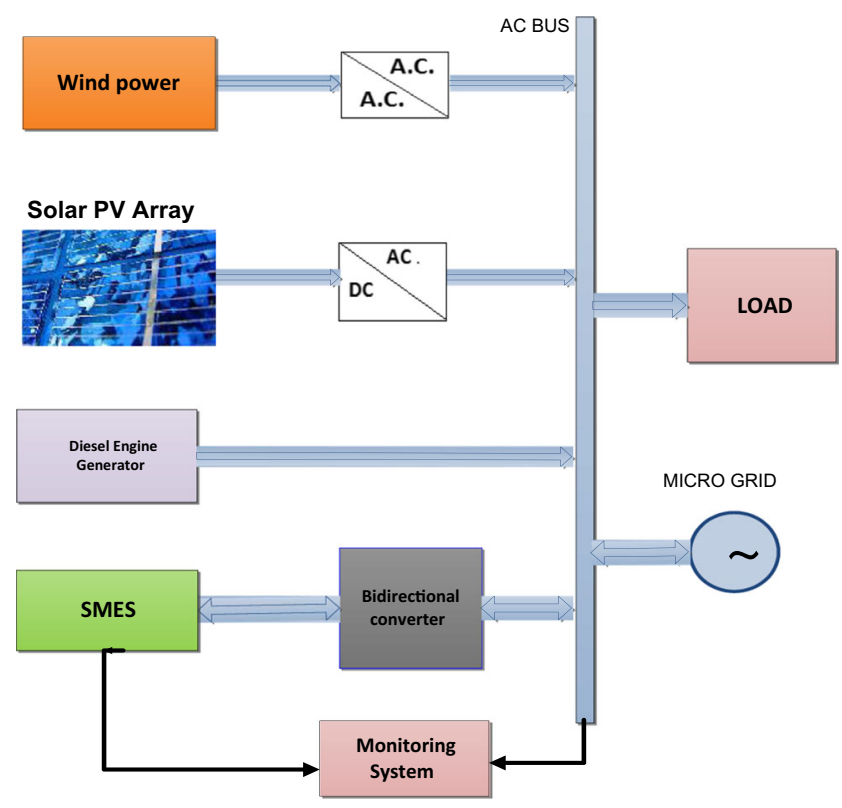

Fig. 1 Schematic diagram of hybrid Power system with SMES

\section{i Power Generation Sources (Solar PV, Wind, and DEG) ii Storage System \\ iii Power Conditioning System (PCS) and load Demand.}

Power generation sources and storage facility have connected to the local grid. SMES has been consumed and supplying power from the local grid. Modeling of different power generating plants such as $\mathrm{PV}$, wind, DEG, and storage system has been carried out below in this section. Modeling of PCS system has not been considered in this study. It is assumed that all required PCS system is working properly in the system. The system model is also useful for distributed and isolated mode of operation.

\section{Solar Photovoltaic Model}

The Solar PV system is composed with PV arrays, connections and protective parts [13]. Arrays are the combination of solar cells. The equivalent circuit of a PV cell is the combination of a current source in parallel with a diode. The current source output is directly proportional to the light falling on the cell. The equation of ideal solar cell $[1,7]$ that symbolizes the solar cell model is [13]:

$\mathrm{I}=\mathrm{I}_{\mathrm{L}}-\mathrm{I}_{\mathrm{R}}\left[\exp \left(\frac{\mathrm{V}}{\mathrm{AV_{ \textrm {i } }}}\right)-1\right]$

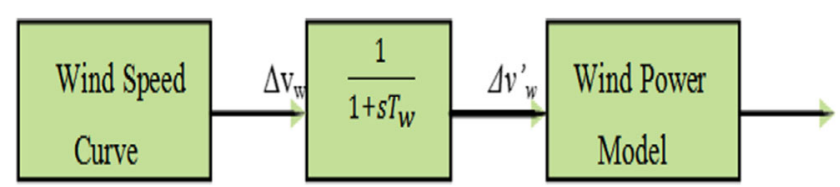

Fig. 2 Wind speed to power generation model [23] 
Fig. 3 Schematic diagram of the SMES unit

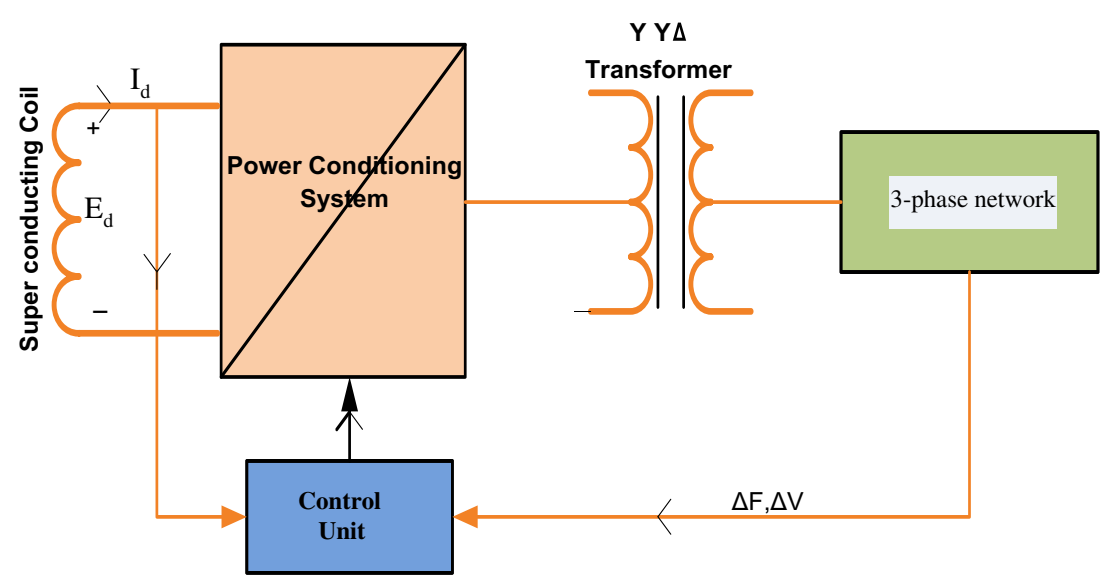

where: "IL" is photocurrent (A); "IR" is reverse saturation current (A);"V" is diode voltage $(\mathrm{V})$; "Vi" is thermal voltage, "A" is diode ideality factor. The composition of solar cells in series and parallel combination with their protection device is known as the solar module [13]. Current-voltage characteristic equation of equivalent circuit for a PV module arranged in series Ns and parallel $\mathrm{Np}$ can be defined as $[7,22]$ :

$$
\begin{aligned}
\mathrm{I}^{\mathrm{M}}= & \mathrm{N}_{\mathrm{p}} \mathrm{I}_{\mathrm{L}}-\mathrm{N}_{\mathrm{p}} \mathrm{I}_{\mathrm{R}}\left[\exp \left(\frac{\mathrm{V}^{\mathrm{M}} / \mathrm{N}_{\mathrm{s}}+\mathrm{I}^{\mathrm{M}} / \mathrm{N}_{\mathrm{s}}}{A V_{\mathrm{i}}}\right)\right] \\
& -\frac{\left(\mathrm{N}_{\mathrm{p}} / \mathrm{N}_{\mathrm{s}}\right) \mathrm{V}^{\mathrm{M}}+\mathrm{I}^{\mathrm{M}} \mathrm{R}_{\mathrm{Se}}}{\mathrm{R}_{\mathrm{Sh}}} .
\end{aligned}
$$

"Np" is cells parallel number; "Ns" is cells series number.

Detailed modeling of PV system has discussed in $[1,13]$.

\section{Wind Speed to Power Conversion Model}

Wind velocity to power conversion model has been used to represents the wind power model. The detailed modeling of wind power has been already discussed in previously reported research work [16]. Wind velocity is the combination of following four components: average speed (vwa), wind speed ramp (vwr), wind gust (vwg) and wind turbulence (vwt) in general. Therefore, the resultant wind velocity can be given in [12, 23]:

$\mathrm{v}_{\mathrm{w}}(\mathrm{t})=\mathrm{v}_{\mathrm{wa}}(\mathrm{t})+\mathrm{v}_{\mathrm{wr}}(\mathrm{t})+\mathrm{v}_{\mathrm{wg}}(\mathrm{t})+\mathrm{v}_{\mathrm{wt}}(\mathrm{t})$

To approximate the fluctuation effects low pass filter is deployed in the wind power conversion model as shown in Fig. 2. The following equation governs the power generated by wind turbine:

$\mathrm{P}_{\mathrm{w}}=\mathrm{c}_{\mathrm{p}}(\lambda, \beta) \frac{\sigma}{2} \pi \mathrm{r}^{2} \mathrm{v}_{\mathrm{w}}^{3}$

where $c_{p}$ is the power coefficient of wind turbine and $\lambda$ is the tip speed ratio, which is defined by:

$\lambda=\frac{\omega_{\mathrm{T}} \mathrm{r}}{\mathrm{v}_{\mathrm{w}}}$

\section{Diesel Engine Generator Model}

Diesel engine power generation is governed by following equation generally.

$\Delta P_{d}=-\left(\frac{1}{R}+\frac{K_{I}}{s}\right)\left(\frac{1}{T_{s g} s+1}\right)\left(\frac{K_{\mathrm{DEG}}}{T_{\mathrm{DEG} s}+1}\right) \Delta f_{e}$
Fig. 4 SMES control unit block diagram [16]

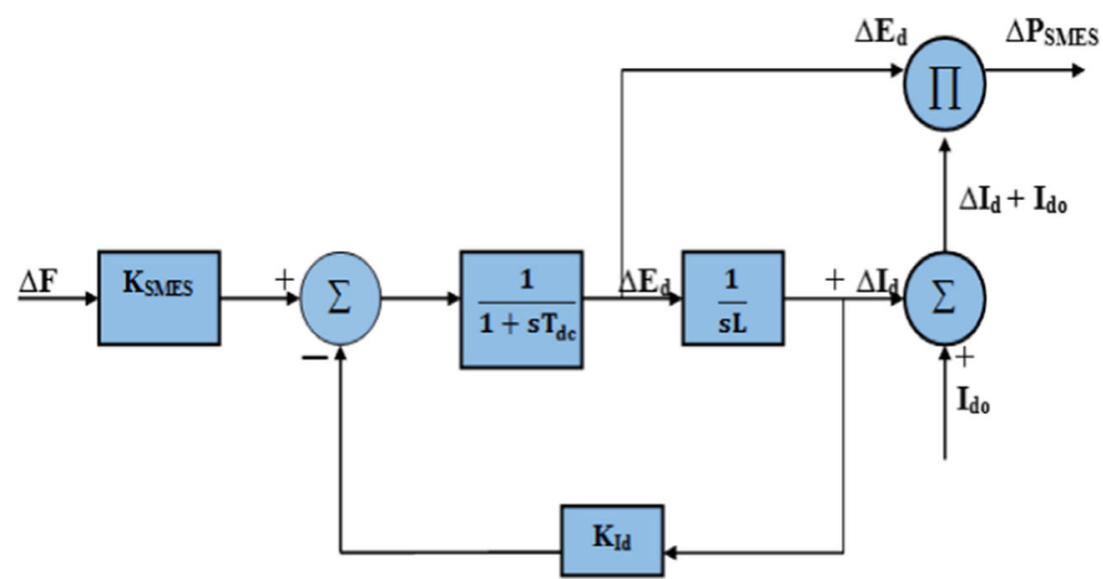




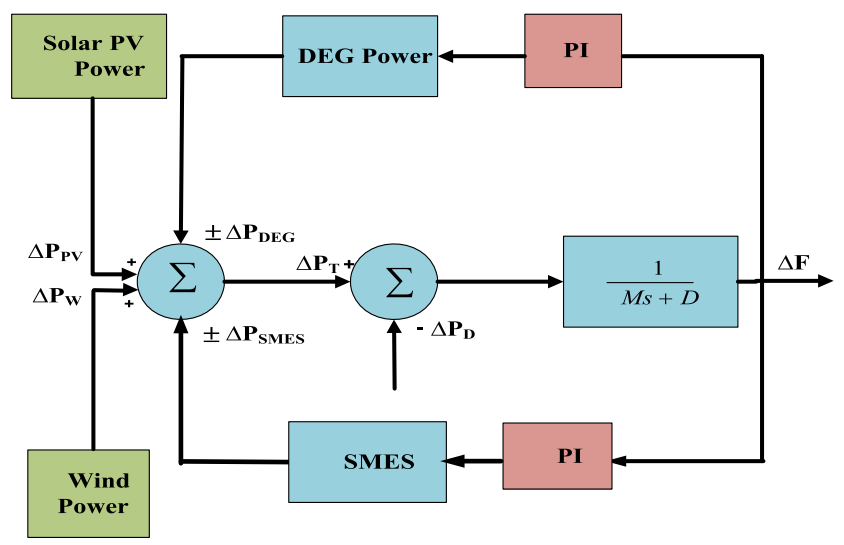

Fig. 5 Mathematical model of Micro-grid connected HPS

where, $\mathrm{R}$ is the speed regulation. DEG automatically starts up with proper control.

\section{SMES Model}

Schematic diagram of SMES model has been shown in Fig. 3. The SMES model has been divided into three parts mainly. First is as superconducting coil i.e. also known as the heart of the system and second deals with power conditioning system. The third is control unit which has been shown in Fig. 4 separately. A detailed description of SMES modeling is well explained in [16, 24]. From Fig. 3, DC voltage is given by:

$\mathrm{E}_{\mathrm{d}}=2 \mathrm{~V}_{\mathrm{d}} \cos \alpha-2 \mathrm{I}_{\mathrm{d}} \mathrm{RC}$

Where $\mathrm{E}_{\mathrm{d}}$ is the DC voltage applied to the inductor in $\mathrm{KV}$, $\alpha$ is the firing angle in degrees, $\mathrm{I}_{\mathrm{d}}$ is the current flowing through the inductor in $\mathrm{kA}, \mathrm{RC}$ is equivalent commutating resistance in $\mathrm{k} \Omega$ and $\mathrm{V}_{\mathrm{do}}$ is the maximum circuit bridge voltage in $\mathrm{kV}$ [16]. Controlling of charging and discharging of the superconducting coil is done with the altering of commutation angle $\alpha$. The converter operates in the charging mode (converter mode), when $\alpha$ is less than $90^{\circ}$ and in discharging mode (inverter mode) when $\alpha$ greater

Table 1 Parameters of GA

\begin{tabular}{ll}
\hline Parameter & Value \\
Population size & 30 \\
Max no. of generation & 50 \\
Mutation probability & 0.15 \\
Crossover probability & 0.8 \\
Length of chromosomes & 8 bits \\
No. of variables & 4 \\
Maximum iteration & 30 \\
\hline
\end{tabular}

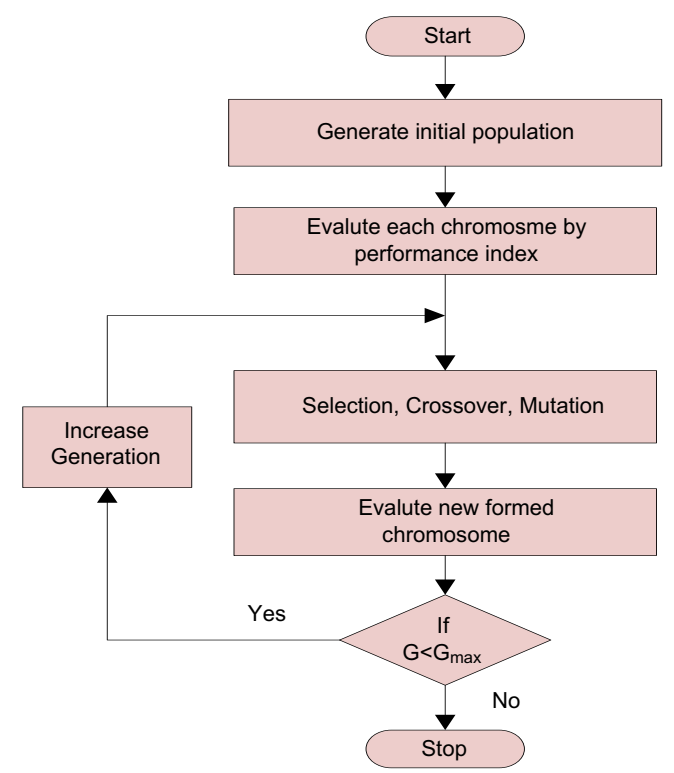

Fig. 6 Flowchart of Genetic Algorithm

than $90^{\circ}[14,21]$. When there is a drop in frequency, power is supplied back into the system. The direction of current flowing through inductor and thyristor does not change suddenly, so the control voltage is negative in nature. The

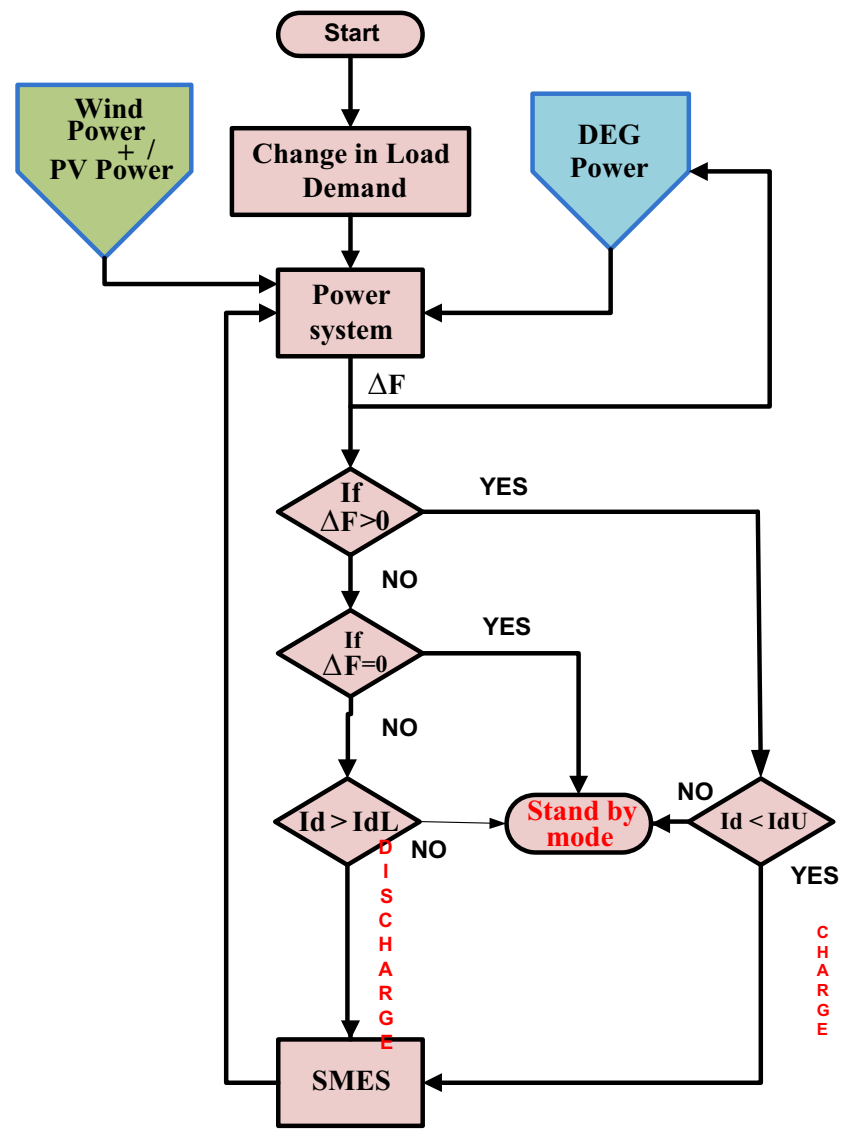

Fig. 7 Flow chart of the operation strategy 
Table 2 Rating and parameters of hybrid model

\begin{tabular}{ll}
\hline Parameter & Value (Rating) \\
\hline System power rating & $2 \mathrm{MW}$ (Base) \\
Capacity of SMES & $2 \mathrm{KA}$ \\
Initial Inductor current(Ido) & $100 \mathrm{KW}$ \\
Upper limit of Inductor & $150 \%$ of Initial \\
current(IdU) & inductor current \\
Lower limit of Inductor & $30 \%$ of Initial \\
current (IdL) & inductor current \\
M & 0.12 \\
D & 0.1 \\
K & 1 \\
$T_{\text {DEG }}$ & $0.5 \mathrm{~s}$ \\
R & 0.5 \\
DEG Power & $250 \mathrm{KW}$ \\
Peak PV Power & $200 \mathrm{KW}$ \\
Wind power & $160 \mathrm{KW}$ \\
\hline
\end{tabular}

incremental change in the voltage applied to the inductor is expressed as:

$$
\Delta \mathrm{E}_{\mathrm{d}}=\left[\frac{\mathrm{K}_{\mathrm{SMES}}}{1+\mathrm{sT}_{\mathrm{dc}}}\right] \Delta \mathrm{F}
$$

Where, $\Delta \mathrm{E}_{\mathrm{d}}$ is the incremental change in converter voltage, $\mathrm{Tdc}$ is the converter time delay, $\mathrm{K}_{\mathrm{SMES}}$ is the control loop gain and $\Delta \mathrm{F}$ is the actuating signal to the control unit of SMES. The inductor current deviation $\left(\Delta \mathrm{I}_{\mathrm{d}}\right)$ is calculated by following Eq. 9:

$$
\Delta \mathrm{I}_{\mathrm{d}}=\frac{\Delta \mathrm{E}_{\mathrm{d}}}{\mathrm{sL}}
$$

The overall change in SMES power flow $\triangle \mathrm{P}_{\text {SMES }}$ due to system frequency $(\Delta \mathrm{F})$ change is shown below Eq. 10:

$$
\begin{aligned}
\Delta \mathrm{P}_{\mathrm{SMES}} & =\Delta \text { Ed. } \mathrm{I}_{\mathrm{d}} \\
\mathrm{I}_{\mathrm{d}} & =\mathrm{I}_{\mathrm{do}}+\Delta \mathrm{I}_{\mathrm{d}}
\end{aligned}
$$

Where $I_{d}$ is net inductor current

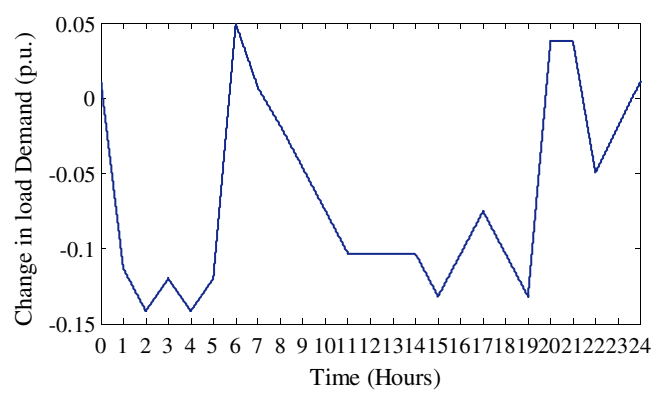

Fig. 8 Load demand Varations profile

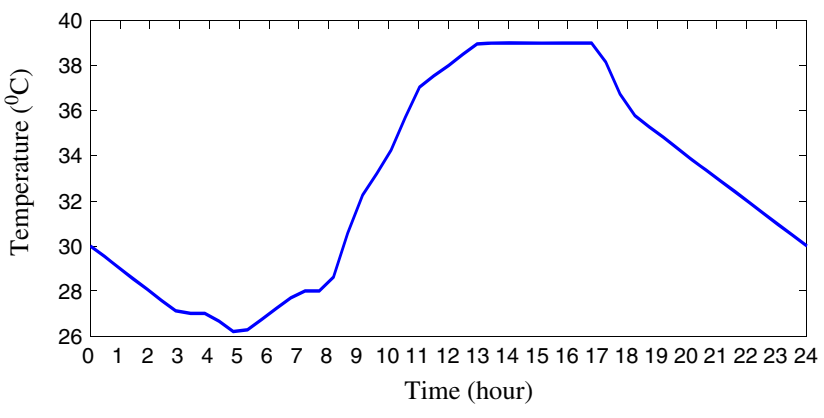

Fig. 9 Temperature Profile throughout a typical day

\section{Mathematical Modelling of HPS}

This subsection described the mathematical model of HPS. The transfer function based model of HPS has been shown in Fig. 5. Assumed that, PCS is properly working at their defined positions. Table 1 shows the parameters of HPS used in modeling. The load generation balance must be maintained for the smooth operation of the grid-connected system. The control strategy is determined by the controlling error which is the difference between the change in load demand $\left(\Delta \mathrm{P}_{\mathrm{D}}\right)$ and change in net power production $\left(\Delta \mathrm{P}_{\mathrm{T}}\right)$.

$\Delta \mathrm{P}_{\mathrm{T}}=\Delta \mathrm{P}_{\mathrm{PV}}+\Delta \mathrm{P}_{\mathrm{w}} \pm \Delta \mathrm{P}_{\mathrm{DEG}} \pm \Delta \mathrm{P}_{\mathrm{SMES}}$

$\Delta \mathrm{P}_{\mathrm{S}}=\Delta \mathrm{P}_{\mathrm{T}}-\Delta \mathrm{P}_{\mathrm{D}}$

where $\Delta \mathrm{P}_{\mathrm{S}}$ is net power controlling error.

Following equation finds the change in frequency variation $(\Delta \mathrm{F})$ :

$\Delta \mathrm{F}=\frac{\mathrm{K}_{\mathrm{PS}}}{1+\mathrm{T}_{\mathrm{PS}}} . \Delta \mathrm{Ps}$

Since an inherent time delay exists between system frequencies. Transfer function for system frequency variation to per unit power deviation is expressed in below equation:

$$
\begin{aligned}
& \Delta \mathrm{F}=\frac{1}{\mathrm{D}+\mathrm{sM}} \cdot \Delta \mathrm{P}_{\mathrm{S}} \\
& \mathrm{D}=\frac{1}{\mathrm{~K}}{ }_{\mathrm{PS}}, \mathrm{M}=\frac{\mathrm{T}_{\mathrm{PS}}}{\mathrm{K}_{\mathrm{PS}}}
\end{aligned}
$$

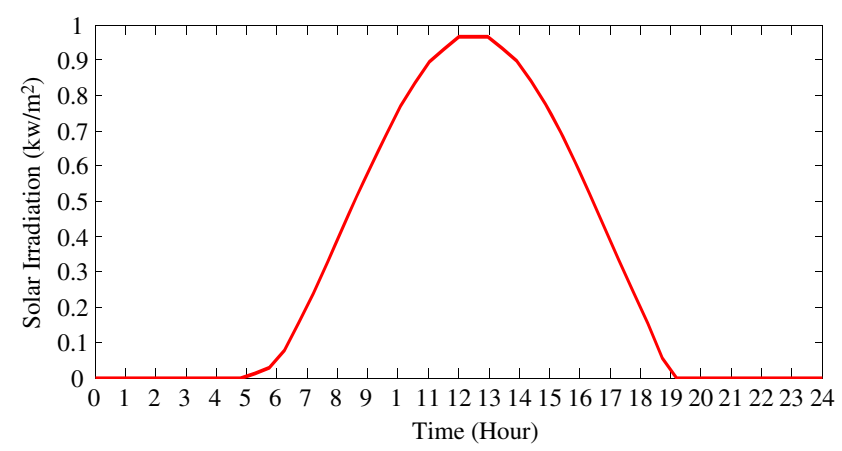

Fig. 10 Solar Irradiation proflie throughout a day 


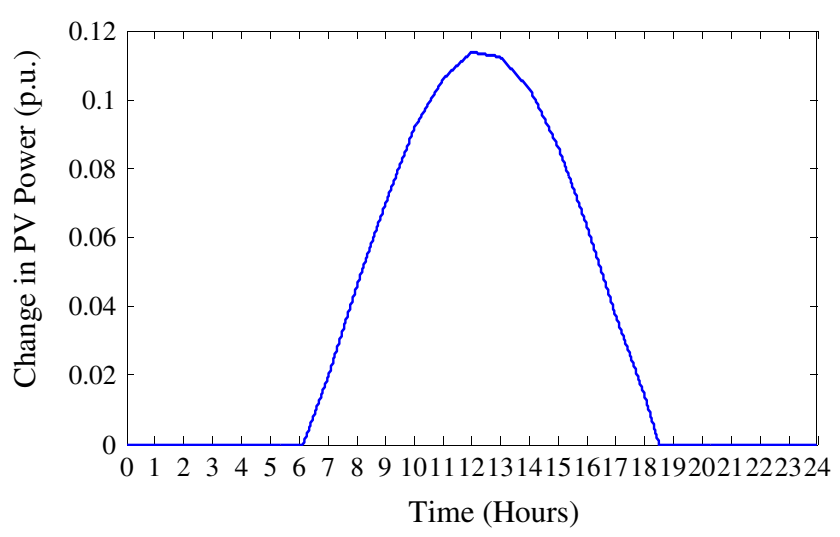

Fig. 11 PV Power profile for a typical day

Where $\mathrm{M}=$ The equivalent inertia constant (p.u) \& $\mathrm{D}=$ Damping constant (p.u).

\section{Optimal Design of PI Controllers with Genetic Algorithm (GA)}

The actuating signal for PI controller is the summation of proportional and integral of the error signal. Gain of PI controller is shown as:

$G(s)=K_{P}+\frac{K_{I}}{s}$

Where $\mathrm{K}_{\mathrm{P}}$ and $\mathrm{K}_{\mathrm{I}}$ are the Proportional(P) and Integral(I) gain constant respectively.

\section{Objective Function}

The tuning of PI controller depends upon two parameters $\left(\mathrm{Kp} \& \mathrm{~K}_{\mathrm{I}}\right)$ to regulate the change in frequency error $(\Delta \mathrm{f})$. The values of PI parameters are calculated through genetic algorithm optimization technique. In order to achieve, optimum system response and to minimize the frequency error integral time square error method is used here as shown below:

$F(X)=I T E S=\int_{O}^{\infty} t *(\Delta f)^{2} d t$

$\mathrm{X}$ is the variable in terms of the values of $\mathrm{K}_{\mathrm{p}}$ and $\mathrm{K}_{\mathrm{i}}$. The optimal values of PI parameter are determined with the genetic algorithm optimization technique.

\section{Genetic Algorithms}

Genetic algorithms (GA) are a biologically inspired algorithm. GA search algorithm is based on the mechanics of natural selection that copycats biological evolution. GA

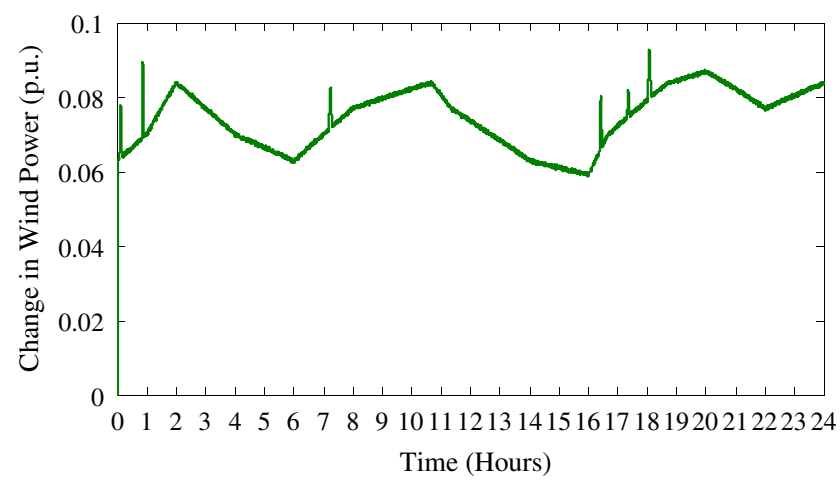

Fig. 12 Wind Power profile through a day

combines the survival of the fittest among string structures with a structured randomized information exchange to develop a search algorithm with the innovative flairs of human search. Generally, GA used to find out high-quality optimization and solution in search problems. In each iteration, a new set of artificial string is formed using bits and pieces of the fittest of the previous [25, 26]. A simple GA that produces good results in many real-world problems is composed of three operations as 1) Selection or Reproduction. 2) Crossover. 3) Mutation. Reproduction or selection is a process in which individual strings are copied according to their objective function values. After reproduction, simple crossover carried out in two steps. First, a member of newly reproduced strings in the mating pool is mated at random. Second, each pair of strings undergoes crossing over as an integer position. Mutation operator shields beside irrecoverable loss [25]. Figure 6 shows the flowchart of Genetic Algorithm.

\section{Step Procedures}

Step procedure used for tuning of PI controllers with GA is shown below

i. Initialize the population for variables(x) with 8 bits length of chromosomes for each one. Size of the population is in between 15-30 and set iteration (r) $=1$

ii. Calculate the fitness function based on Eq. 9 for all candidate solutions.

iii. Sort all the fitness functions in ascending order. $\left.\left[\mathrm{F}_{1}^{\mathrm{r}}(\mathrm{x}), \mathrm{F}_{2}^{\mathrm{r}}(\mathrm{x}),\right] \ldots \mathrm{Fp}^{\mathrm{r}}(\mathrm{x}),\right]$, Best cost $=\mathrm{F}_{1}^{r}(\mathrm{x})$, best candidate solution $=\mathrm{x}$, where $\mathrm{r}$ is no of iterations.

iv. Set the probability of chromosomes and mutation

v. Select all the parent chromosomes and apply crossover on each candidate solution

vi. Apply mutation to the all chromosome

vii. Again calculate fitness function for all candidate solution and sort them in ascending order $\left[\mathrm{F}_{1}^{\mathrm{r}+1}(\mathrm{x})\right.$, $\left.\left.\mathrm{F}_{2}^{\mathrm{r}+1}(\mathrm{x}),\right] \ldots \mathrm{F}_{\mathrm{p}}^{\mathrm{r}+1}(\mathrm{x}),\right]$, 
Fig. 13 Frequency Response with increased step load (peak load.)

Fig. 14 SMES power injection response during the peak load (0.25p.u.)

Fig. 15 Frequency Response with decreased step load (Off peak load.)
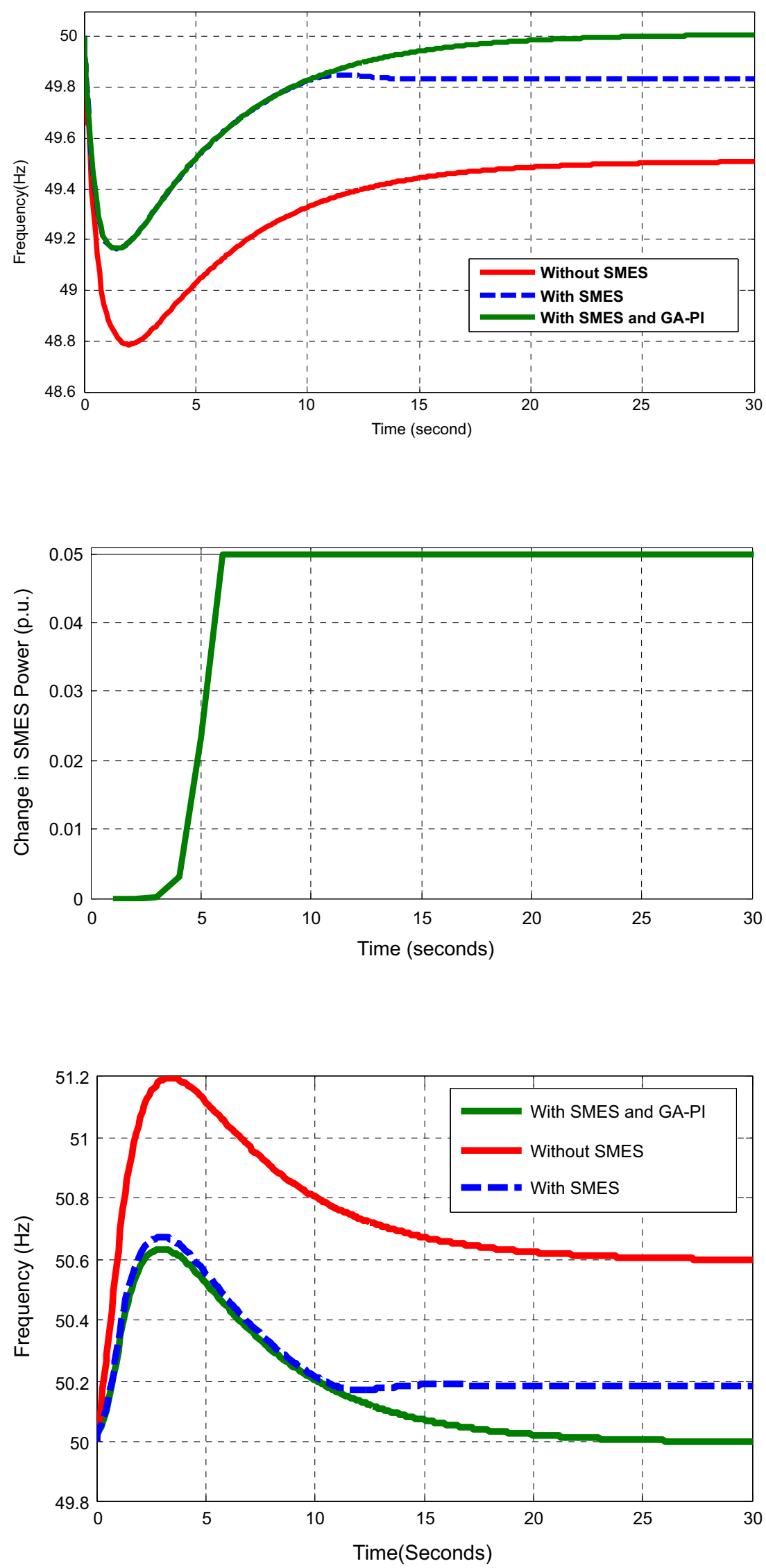


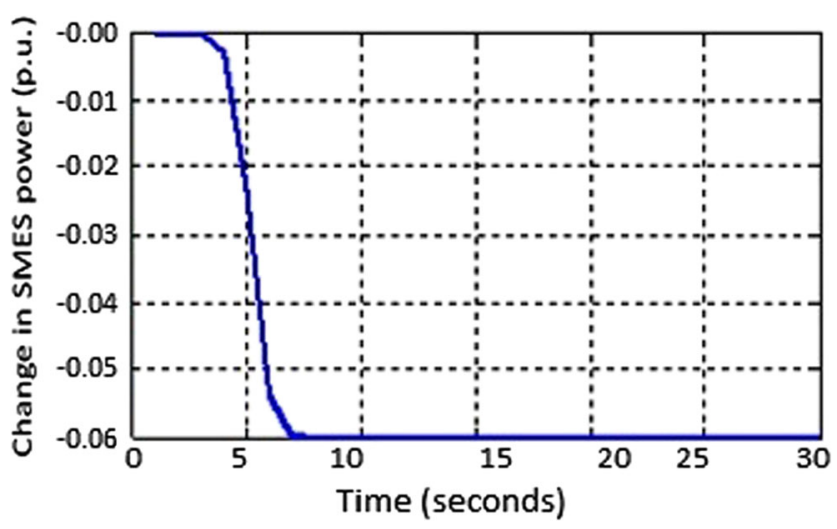

Fig. 16 SMES power consumption response during the off peak load

viii. If, $\mathrm{F}_{1}^{\mathrm{r}+1}(\mathrm{x})<$ Best Cost, Update Best cost $=\mathrm{F}_{1}^{\mathrm{r}+1}(\mathrm{x})$ $\&$ best candidate solution $=\mathrm{x}$, Else, best $\cos t=$ best cost

ix. Put $r=r+1$, if no of iteration(r) $<$ max iter, go to step 2

Else, stop and store best cost and best candidate solution.

Parameters of GA used to tune the PI controllers are given in Table 1.

\section{Operating Strategy}

In this section, operation strategy for considered HPS is discussed and flow chart has been shown in Fig. 7. The system/grid frequency is very sensitive to load demand change. Therefore, whenever variations in load demand occur, system frequency changes according to it. Grid frequency must lie within the acceptable range for stable and smooth operation of HPS. In order to neutralize, the frequency fluctuations, the power supply should be controlled according to load variations. When the frequency of the grid is reported below $50 \mathrm{~Hz}$ or change in frequency is negative, SMES starts injecting the power into the grid. However, SMES

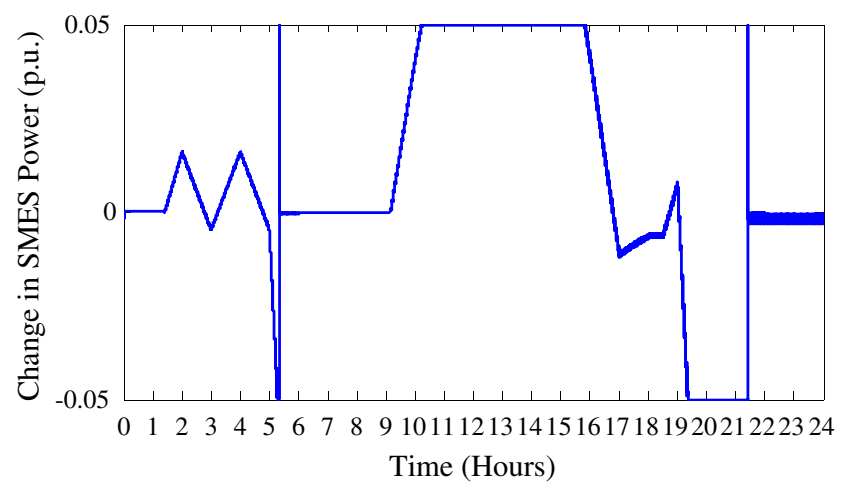

Fig. 17 Variation of SMES Power in both charging \& discharging mode

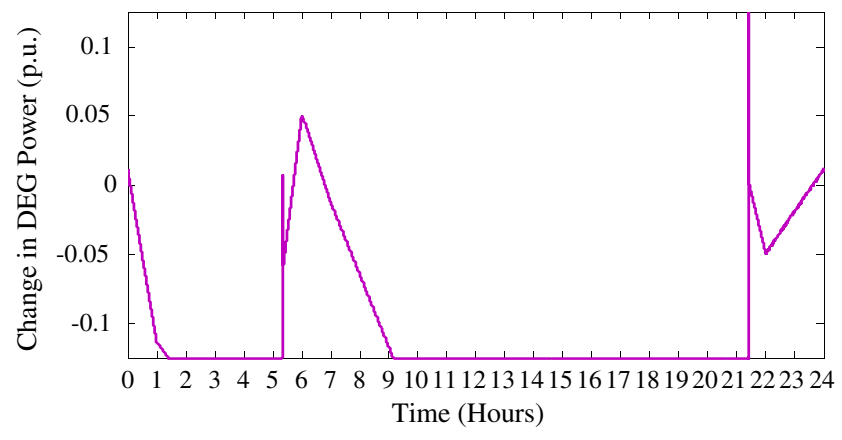

Fig. 18 Change in DEG. Power output

unit must check the status of superconducting coil current (Id) and verify its capacity to lower limit of the inductor current (IdL). If Id > IdL, SMES will turn on and start discharging; otherwise, it will remain in off mode. In another case, when the frequency of the grid is reported above 50 $\mathrm{Hz}$ or change in frequency is positive, SMES starts absorbing (charging the SMES coil) some excess power from the grid. Before consuming the power, Id has to check and compared to its upper limit of the inductor current (IdU). If Id $<$ IdU then SMES control unit allows to charge the coil otherwise SMES remains in off mode. During constant frequency operation (change in frequency zero), SMES neither in charge mode nor in discharging mode. It stays remains in standby mode conditions.

\section{Simulation Results and Analysis}

In this section, simulation results of considered HPS have been analyzed. Parameters and system ratings has been shown in Table 2. Simulations of HPS are carried out in two different scenarios as follows:

\section{A. Scenario 1- HPS with Solar PV+DEG+SMES \\ B. Scenario 2- HPS with Solar PV+Wind+SMES}

Each scenario is simulated in two phases of studies. The first phase is the steady-state stability analysis using step load

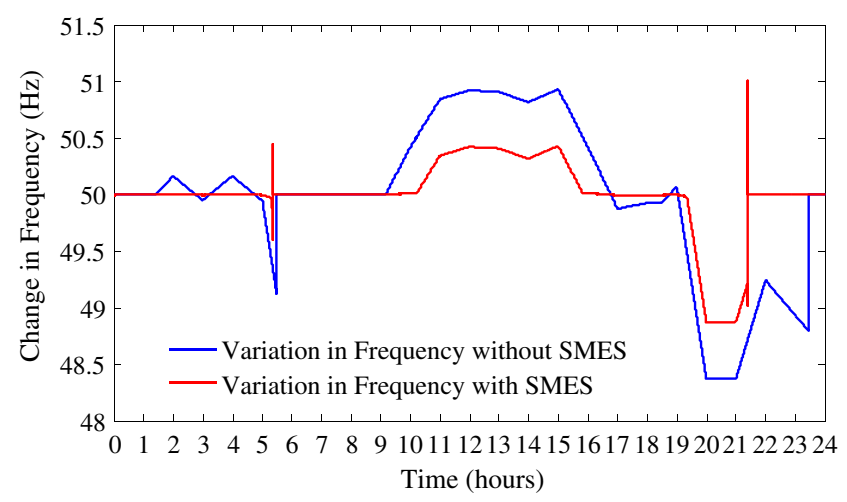

Fig. 19 The frequency response of the system throughout the day 
Fig. 20 Frequency Response with increased step load (peak load.)

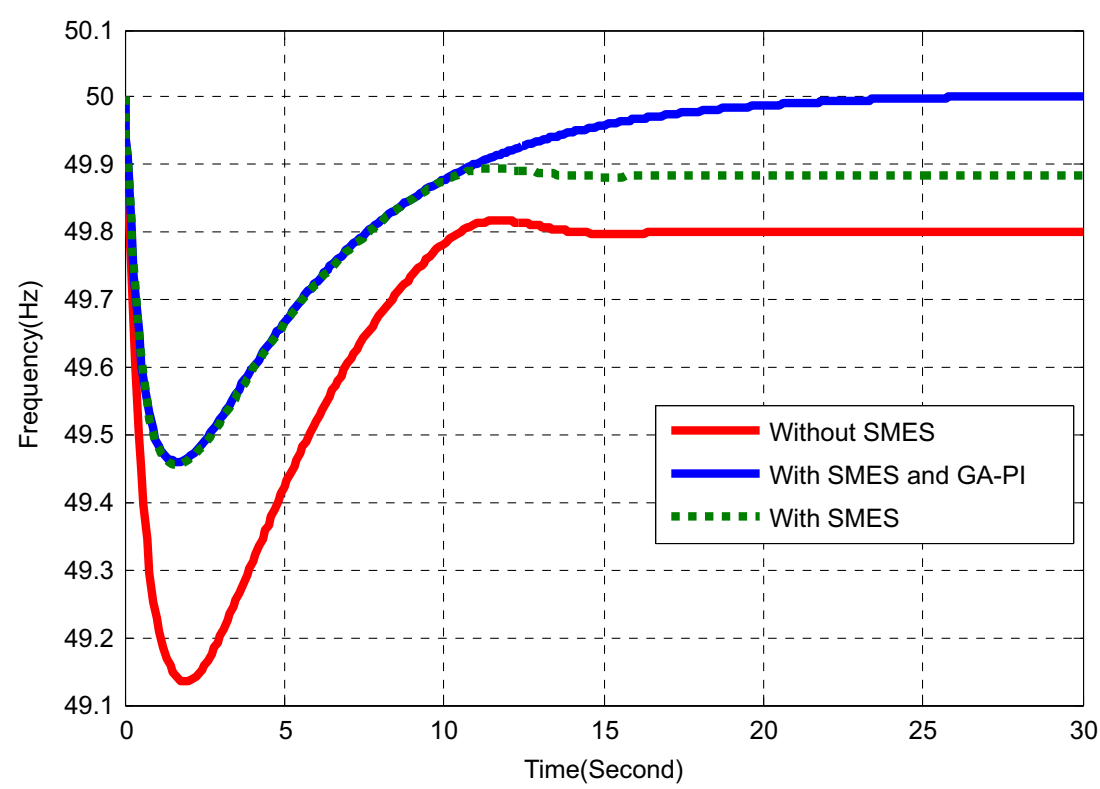

response of system model. The second is the dynamic stability analysis with 24 hours simulations with random variation in load demand. Phase I is further divided into two cases as step load analysis during the peak load and off-peak load time. Variations of a typical day load demand have been shown in Fig. 8. The temperature and solar irradiations variations for a typical day have been shown in Figs. 9 and 10 respectively. The power produced with $\mathrm{PV}$ and wind plant has been shown in Figs. 11 and 12 respectively.

\section{Scenario 1- HPS with Solar PV+DEG+SMES}

Scenario 1, consists the study of HPS containing the solar PV, DEG, and SMES storage facilities. The penetration of solar power is hundred percentage of generated PV power. The study of this scenario is carried out in two phases with two cases as discussed below:

\section{Phase I: Steady state Stability Analysis}

Considered HPS is analyzed through step load change response during peak and off-peak load demand with the presence or absence of SMES. The system is simulated for the duration of has carried 30 seconds.

\section{(i) Case I: During peak load}

Step load change of 0.25 p.u is considered for the analysis of this cases. Due to a sudden rise in load demand, the frequency will go down to below a defined limit. Therefore, to maintain the system
Fig. 21 SMES power injection response during the peak load (0.25p.u.)

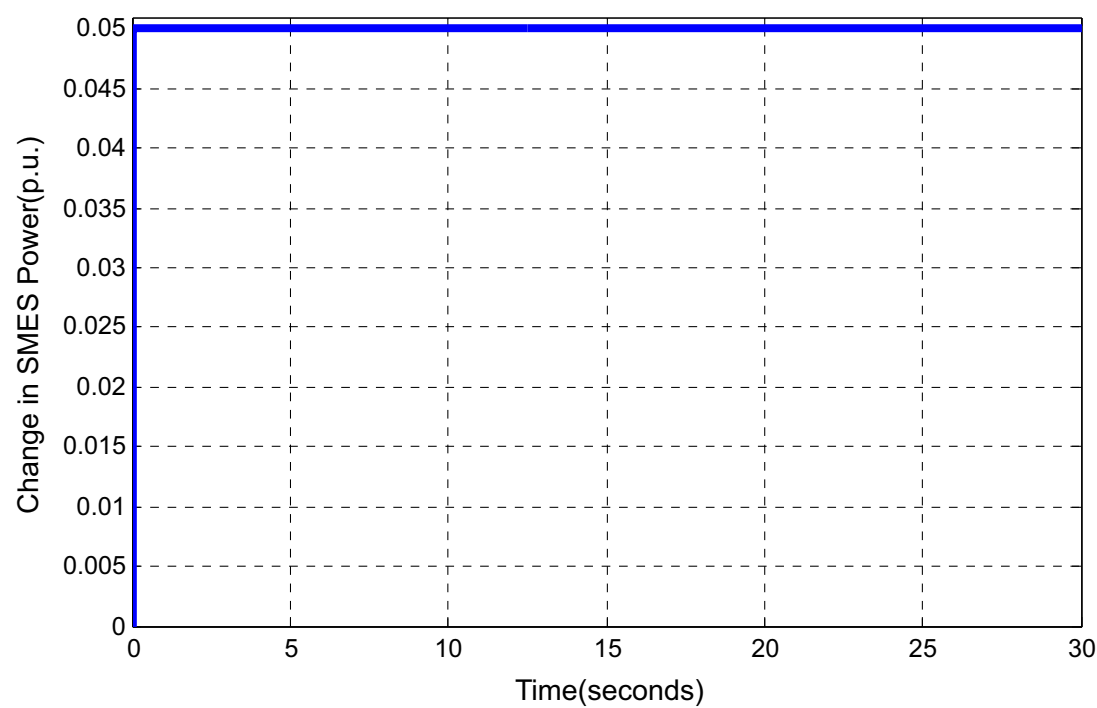


Fig. 22 Frequency Response with decreased step load (Off peak load.)

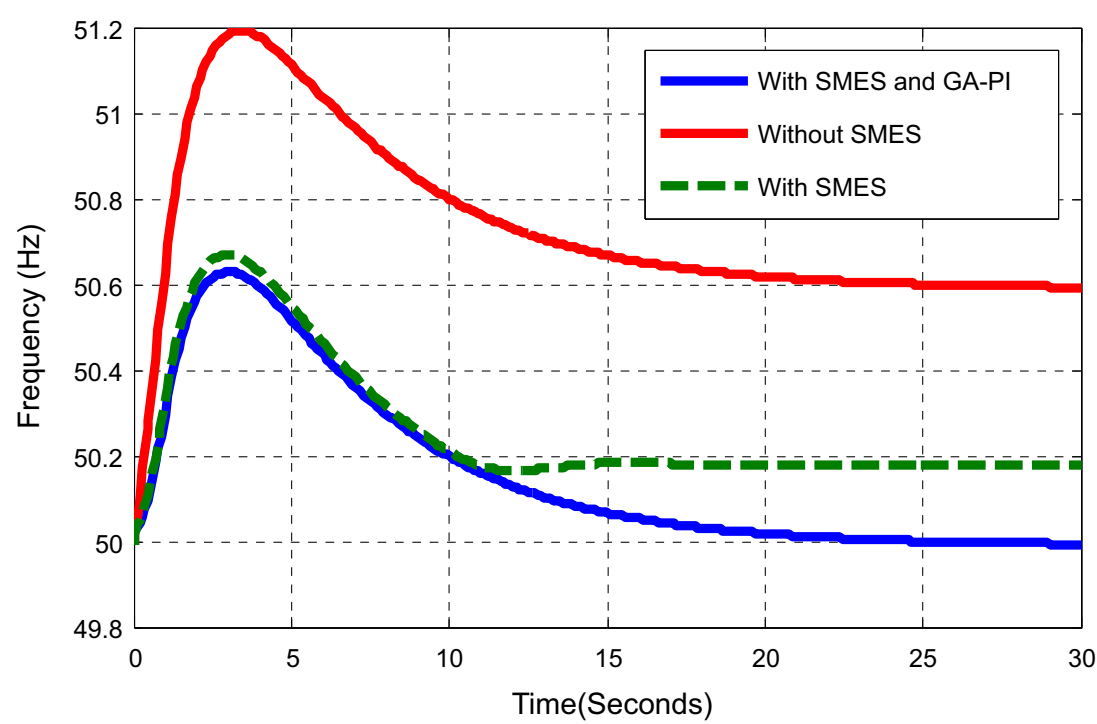

frequency, SMES will start supplying the power into the microgrid. Because of this act, SMES is operating in the discharging mode. Frequency response with the sudden increase in step load demand has been shown in Fig. 13. The effect in frequency response with, without SMES and with GA-PI controller is shown the Fig. 13. From Fig. 13 it is observed that frequency deviation is minimized maximum during the operation of HPS with the combination of optimized controller and SMES. Power injected by the SMES has also shown in Fig. 14.

(ii) Case II: During off peak load

Step load change of 0.045 p.u. has been considered for the analysis of this cases. Due to a sudden decrease in load demand, there is a rise in system frequency is reported. However, to compensate this frequency fluctuations, power generation should be minimized or/and store the energy in SMES. In order to maintain the system frequency, SMES will start consuming the power from the microgrid. This state of SMES is known as the charging mode. The effect in frequency response with, without SMES and with GA-PI controller is shown the Fig. 15. From Fig. 15 it is observed that frequency deviation is minimized maximum in the operation of HPS the combination of optimized controller and SMES. Power absorbed by the SMES with negative sign has also shown in Fig. 16.

\section{Phase II: Dynamic Simulations for 24 Hours}

The considered HPS model has simulated for 24 hours in this phase of the study. The dynamic stability study is carried out with varying load demand and power generations throughout a day. The study is further divided into two cases, i.e. during the increase in load and decrease in load demand.
Fig. 23 SMES power consumption response during the off peak load

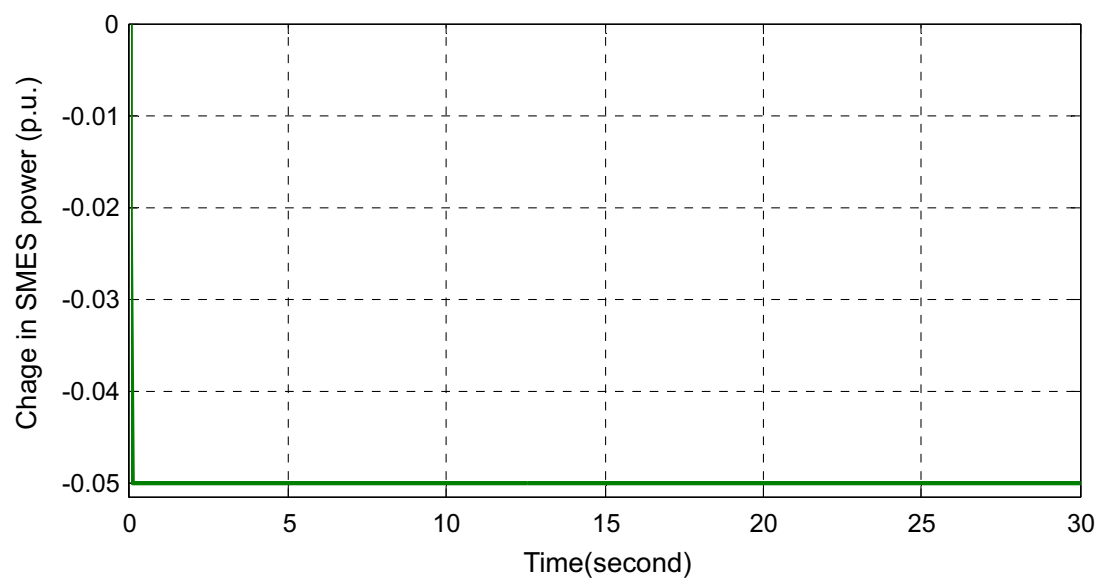




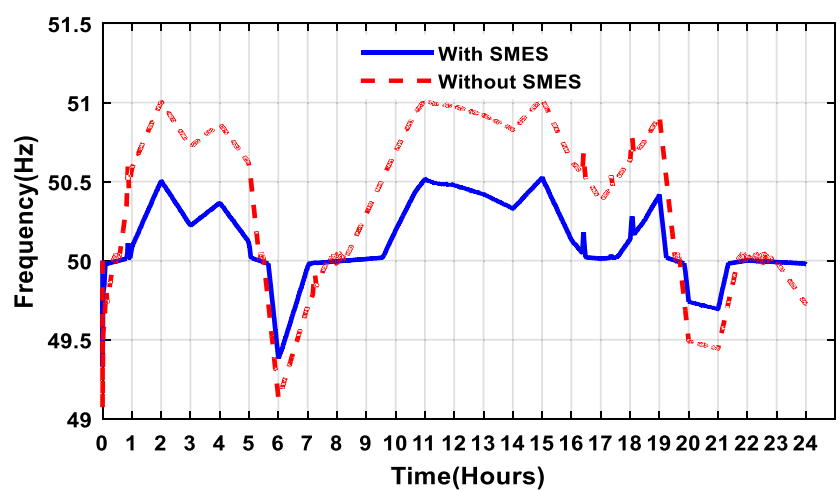

Fig. 24 Frequency response of the system throughout the day

(i) Case I: Increase in load demand

Due to increase in load demand, system frequency decreases. Therefore, power generation should be increased to maintain the frequency. PV power is regularly supplying the power to the system. Due to dip in system frequency, DEG power can be enlarged to supply the power to the system, up to its rated capacity. To compensate the load demand, SMES supplying power to the system as shown in Fig. 17.

(ii) Case II: Decrease in load Demand

Change in frequency increases, as a change in load demand, decreases. So, in order to maintain frequency, the total power generation should be decrease and/or increase the load consumptions. Due to variation in frequency, the net change in DEG power shown in Fig. 18. Power supplied by SMES should be decreasing response reached zero as shown in Fig. 17. However, the surplus power is still more than load demand so for balancing power SMES starts consuming power from the system. Now SMES is in charging mode.

Figure 19 shows the frequency response of the considered HPS including both increase and decrease of the load demand with and without SMES throughout a day. From Fig. 19, it can be observed that frequency fluctuations can be mitigated with the addition of SMES into the system.

\section{Scenario 2- HPS with Solar PV+Wind+SMES}

Scenario 2 consists the study of HPS containing the solar PV, Wind and SMES storage facilities. HPS system is also known as $100 \%$ power generations from renewable. The penetration of solar power is fifty percentage of generated PV power. The study of this scenario is carried out in two phases with two cases as discussed below:

\section{Phase I: Steady state Stability Analysis}

Considered HPS is analyzed through step load change response during peak and off-peak load demand with the

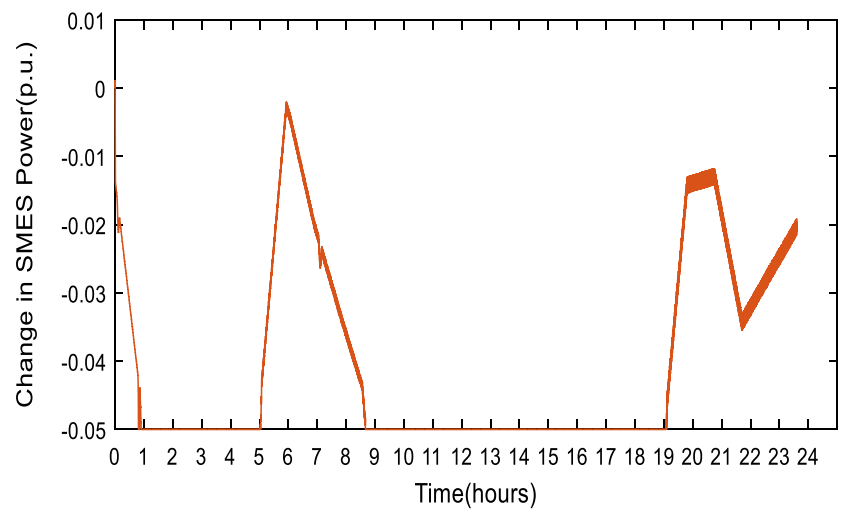

Fig. 25 SMES Power variation in both charging \& discharging mode

presence or absence of SMES. The system is simulated for the duration of has carried 30 seconds.

\section{(i) CASE I: During peak load}

Step load change of 0.25 p.u is considered for the analysis of this cases. The operation of the system is same as discussed in Case I of Phase I of Scenario 1(HPS with Solar PV+DEG+SMES). The effect in frequency response with, without SMES and with GA-PI controller is shown the Fig. 20. From Fig. 20 it is observed that frequency deviation is minimized maximum during the operation of HPS with the combination of optimized controller and SMES. Power injected by the SMES has also shown in Fig. 21.

(ii) CASE II: During off peak load

Step load change of 0.045 p.u. has been considered for the analysis of this subcase. The operation of the system is same as discussed in Case II, Phase I of Scenario 1(HPS with Solar PV+DEG+SMES). The effect in frequency response with, without SMES and with GA-PI controllers are shown in the Fig. 22. From Fig. 22, it is observed that frequency deviation is minimized maximum, in the operation of HPS with the combination of optimized controller and SMES. Power absorbed by the SMES has also shown in Fig. 23.

\section{Phase II: Dynamic Simulations for 24 Hours}

The considered HPS model has simulated for 24 hours in this phase of the study. The dynamic stability study is carried out with varying load demand and power generations throughout a day. The operating scheme in this phase is similar to previous section phase II of Scenario 1- (HPS with Solar PV+DEG+SMES). However, in this study, DEG is not incorporated. Frequency response throughout the day has shown in Fig. 24. SMES power profile during both the charging and discharging mode has shown in Fig. 25. From the above figures, it is 
demonstrated that fluctuations in system frequency can be smoothened or mitigate perfectly with the integration of SMES units.

\section{Conclusion}

The mitigation of frequency fluctuations in micro grid connected PV, wind based hybrid power systems has been analyzed with SMES technology. The performance of the considered system has been assessed with the variable load demand and renewable power sources. The small signal stability analysis is carried out with and without PI controllers. The parameters of PI controllers is optimized with genetic algorithm. Simulation results demostrates that SMES based system gives better frequency response in comparison to the only diesel generator and without SMES. However, it seems that SMES technologies are not so much economically. However, this issue may compensate with its fruitful applications such as fast response, high efficiency, capability of control of real power and reactive power flows. With the emergence of smart grids, this technology is receiving more attention in the field of power and energy systems. Therefore, it is hoped that its potential advantages and environmental benefits will make SMES units a viable alternative for energy storage source.

\section{References}

1. Singh S, Singh AK, Chanana S (2012) Operation and control of a hybrid photovoltaic-diesel-fuel cell system connected to microgrid. IEEE Power India Conf

2. Jae Woong S et al (2013) Synergistic control of SMES and battery energy storage for enabling dispatchability of renewable energy sources. IEEE Trans Appl Supercond 23(2):5701205-5701205

3. Kumar D, Sarkar S (2016) A review on the technology, performance, design optimization, reliability, techno-economics and environmental impacts of hydrokinetic energy conversion systems. Renew Sust Energ Rev 58:796-813

4. Walid O (2010) Performance analysis of grid-Connected photovoltaic systems. Dissertation, University of Waterloo

5. Qi C, Ming Z (2012) Photovoltaic module simulink model for a stand-alone pv system. International conference on applied physics and industrial engineering. Phys Procedia 29:94100

6. Byung-Kwan K et al (2013) Effect of a SMES in Power distribution network with PV system and PBEVs. IEEE Trans Appl Supercond 23(2):5700104-5700104

7. Kim AR et al (2011) Performance analysis of a toroid-type HTS SMES adopted for frequency stabilization. IEEE Trans Appl Supercond 21(2):1367-1370

8. Ali MH et al (2010) An overview of SMES applications in power and energy systems. IEEE Trans Sustain Energy 1(1):38-47
9. Chen L, Liu Y et al (2006) Detailed modeling of superconducting magnetic energy storage (SMES) system. IEEE Trans Power Deliv 21(2):699-710

10. Nakayama T et al (2009) Micro power grid system with SMES and superconducting cable modules cooled by liquid hydrogen. IEEE Trans Appl Supercond 19(2):2062-2065

11. Chanana S, Kumar A (2011) Operation and control of BESS using frequency-linked pricing in real-time market with high wind penetration. Int J Energy Sector Manag 5(4):585-602

12. Singh S, Singh M, Chanana S, Raveendhra D (2014) Operation and control of a hybrid wind-diesel-battery energy system connected to micro-grid. In: International conference on control and automation, robotics and embedded system

13. Singh S, Singh SK, Chanana S, Singh YP (2014) Frequency regulation of an isolated hybrid power system with battery energy storage system. Power and energy systems: towards sustainable energy

14. Ali MH et al (2009) Improvement of wind-generator stability by fuzzy-logic-controlled SMES. IEEE Trans Ind Appl 45(2):10451051

15. Banerjee S, Chatterjee JK, Tripathy SC (1990) Application of magnetic energy storage unit as load-frequency stabilizer. IEEE Trans Energy Convers 5(1)

16. Singh S, Joshi H, Chanana S, Verma RK (2014) Impact of superconducting magnetic energy storage on frequency stability of an isolated hybrid power system. Computing for sustainable global development (INDIACom)

17. Tripathy SC, Kalantar M, Balasubramenian R (1991) Dynamic and stability of wind and diesel turbine generators with superconducting magnetic energy storage unit on an isolated power system. IEEE Trans Energy Convers 6(4)

18. Das S, Devesh S, Singh SP (2015) Single and two area LFC using RBF. In: IEEE International conference on recent developments in control automation and power engineering (RDCAPE), pp 355-360

19. Ansari TMM, Velusami S (2010) Dual mode linguistic hedge fuzzy logic controller for an isolated wind-diesel hybrid power system with superconducting magnetic energy storage unit. Energy Convers Manag 51(1):169-181

20. Pandey RK, Gupta DK (2016) Knowledge domain states mapping concept for controller tuning in an interconnected power network. Int J Electr Power Energy Syst 80:160-170

21. Molina MG, Mercado PE (2011) Power flow stabilization and control of microgrid with wind generation by superconducting magnetic energy storage. IEEE Trans Power Electron 26(2):910922

22. Rawat S, Singh S, Gaur K (2014) Load frequency control of a hybrid renewable power system with fuel cell system. In: Power India international conference (PIICON)

23. Singh S, Singh M, Chanana S, Semwal S (2015) Frequency regulation of isolated hybrid Wind/Diesel, power generation with fuel cell system. Lecture notes in electrical engineering, Springer, 326 pp. $853-862$

24. Ali MH, Tamura J, Wu B (2008) SMES strategy to minimize frequency fluctuations of wind generator system. In: 34th Annual conference of IEEE industrial electronics IECON

25. Gupta DK, Naresh R, Singh MK (2013) Genetic aided tuning of PI controller based AGC for two area interconnected system. In: Proceedings of IEEE 2nd student conference on engineering and systems

26. Goldberg DE (1989) Genetic algorithm in search, optimization and machine learning reading. Addison-Wesley Publishing Company, Inc 


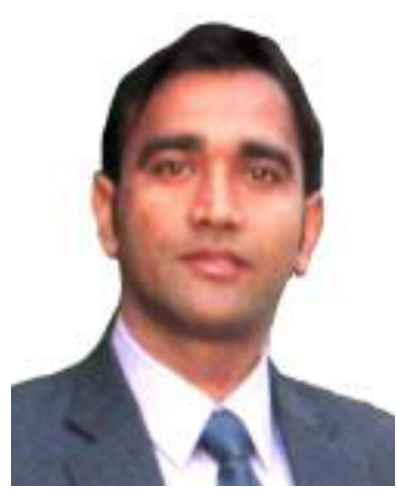

Shailendra Singh was born in Auraiya, India, in 1986. He received the B.Tech. degree in electrical and electronics engineering from the Uttar Pradesh Technical University (UPTU) Lucknow, India, in 2010 and M.Tech degree with specialization in Power system from National Institute of Technology, Kurukshetra, India in 2012. After that $\mathrm{He}$ worked as a assistant Professor in Graphic Era hill University, Bhimtal and Graphic.

Era University Dehradun India from 2012 to 2014 . He has numerous research papers in repute peer reviewed national, international conferences and journals. He is also student member of IEEE(USA), India Smart Grid Forum(ISGF) and various IEEE societies such as power and energy (PES), Industrial and Applications (IAS) and Electrification and Transportation. Currently he is perusing Ph.D degree in department of electrical engineering of Indian Institute of Technology (BHU) Varanasi, India.

His research interests include Operation and control of Power system, Smart distribution system ,energy Storage System, Integration of Renewable Power Sources and MicroGrids.

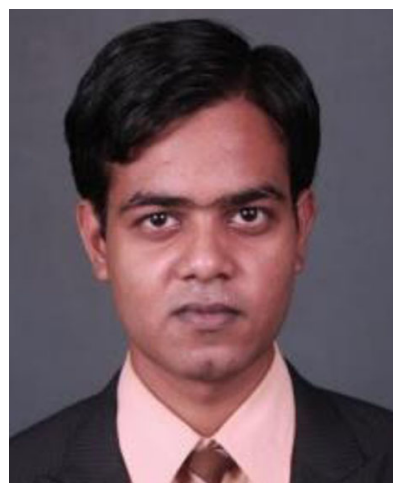

Rohit Kumar Verma received his graduation in electrical engineering from Govind Ballabh Pant Engineering College, Pauri, India and Master's degree from Institute of Technology Roorkee, India. He has two years teaching experience. $\mathrm{He}$ is currently pursuing his $\mathrm{PhD}$ degree from Indian Institute of Technology (Indian School of Mines), Dhanbad, India. His current research interests Mini Grids, Renewable Energy and power systems.

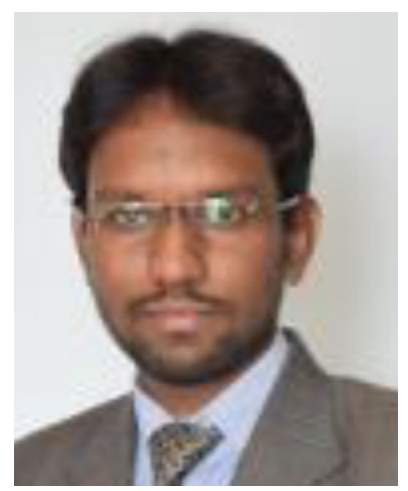

Ashish Kumar Shakya was born in Kanpur, India, in 1989. He received the B.Tech. degree in Electrical \& Electronics engineering from UPTU, Lucknow, India, in 2010, and the M.Tech. degree in electrical engineering from the National Institute of Technology (NIT) Kurukshetra, Haryana, India, in 2012. Currently he is Assistant Professor in the Department of Electrical Engineering, GLA University, Mathura, India. His current research interests Micro Grids Control, Nonlinear Control, Power Electronics and Electrical Machines.

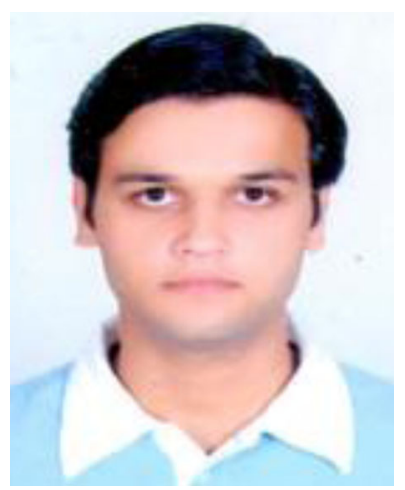

Satyendra Pratap Singh was born in Varanasi, India, in 1985. He received the B.Tech. degree in electrical engineering from the Uttar Pradesh Technical University (UPTU) Lucknow, India, in 2007, and the M.E. degree in electrical engineering with specialization in power system and electric drives from the Thapar University, Patiala, India, in 2009.

$\mathrm{He}$ is currently pursuing the Ph.D. degree in electrical engineering with specialization in power system from the Indian Institute of Technology (BHU) Varanasi, India. Hisresearch interests include wide area measurement in power system, power system operation, applications of AI in power system optimization. 